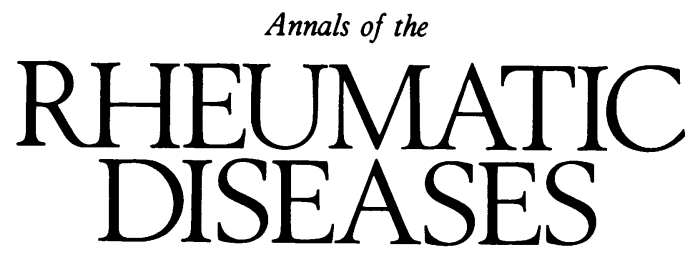

\title{
Leader
}

\section{Sex hormone modulation in systemic lupus erythematosus: still a therapeutic option?}

The influence of sex hormones on the immune system and the marked difference in the prevalence of specific autoimmune diseases between the two sexes have long been recognised. ${ }^{1}$ Women are affected much more than men by diseases of the immune system, particularly systemic lupus erythematosus (SLE), ${ }^{2}$ the prototype 'autoimmune' disease. Systemic lupus erythematosus is most prevalent in the childbearing years with a female:male sex incidence of 9:1. This female to male ratio is much reduced in prepubertal children and after the menopause. ${ }^{1-3}$

Menstruation may be associated with adverse symptomatology in $60 \%$ of lupus patients ${ }^{4}$ and seems to be limited to the 10 days immediately before the start of bleeding. Increased joint pains, fevers, malaise, and behaviour disturbances may be noted. During pregnancy, and especially in the puerperium, 'flares' of the disease may also occur. ${ }^{5}$

The use of conjugated symmetric oestrogens for birth control may also be associated with such 'flares', ${ }^{6}$ and it has been suggested that oral contraceptives may be associated with the development of such complications as chorea ${ }^{7}$ and thromboembolism in some subjects with autoimmune disorders, particularly in the subset of systemic lupus erythematosus with antiphospholipid antibodies. ${ }^{89}$ Hormonal studies in lupus patients have shown that patients of both sexes have raised concentrations of $16 \alpha$-hydroxyoestrone, while women, additionally, have increases of oestriol. ${ }^{10} \mathrm{~A}$ compensatory decrease in cathecol or 2-hydroxylated oestrogens has also been noted. ${ }^{11}$

How these hormones modulate the immune response is unclear, but several differing mechanisms may interact. There may be a relation with steroid receptors: sex steroid receptors have been found on the thymus ${ }^{12}$ and oestrogen receptors are localised specifically to the OKT8+ (suppressor/cytotoxic) subset of $\mathrm{T}$ cells. ${ }^{13}$

Genetically induced hyperoestrogenicity found in men with the Klinefelter's syndrome may also perhaps be important in the development of systemic lupus erythematosus, ${ }^{14} 15$ as well as rheumatoid arthritis in these patients, ${ }^{16} 17$ and a role for the $\mathrm{X}$ chromosome in pathogenesis has been suggested.

In addition to oestrogen abnormalities, studies of androgen metabolism in systemic lupus erythematosus have shown that the oxidation of testosterone at C-17 is increased only in women with active disease. ${ }^{18}$

Data suggest that there are fundamental differences in sex steroid metabolism in systemic lupus erythematosus, particularly in women with active disease, and these findings prompted the use of compounds with potent antioestrogen or proandrogenic effects in the control and treatment of the condition.

\section{Treatment}

ANDROGENS

Androgenic substances have proved disappointing as modulators of human systemic lupus erythematosus, either because of lack of therapeutic effects or because of unacceptable side effects. Two such compounds have been tried over the past few years, both weak androgens with anabolic properties: nandrolone decanoate and danazol.

Nandrolone decanoate (19-nortestosterone decylate), although effective in NZB/NZW mice, ${ }^{19}$ had no demonstrable clinical effects when used on eight female patients with systemic lupus erythematosus. ${ }^{20}$

Recent data on the use of synthetic androgens like 19. nortestosterone in the treatment of male lupus patients has shown that their use results in overall worsened disease (Lahita $\mathbf{R}$, personal communication). The apparent exacerbation of the disease in these men coincides with a lowered free testosterone and low luteinising hormone concentration. The latter indicates that nandrolone is a potent androgen, suppressing free testosterone secretion, and that this effect may be associated with a worsened disease in men as the clinical course of the disease did not correlate with laboratory data (Lahita $\mathrm{R}$, unpublished data).

Danazol, a heterocyclic steroid related clinically to $17 \alpha-$ ethinyltestosterone, has antigonadotrophic effects, suppressing follicle stimulating hormone and luteinising hormone.

It was ineffective in murine lupus in one study, ${ }^{21}$ but there was considerable clinical improvement in seven women with mildly active systemic lupus erythematosus ${ }^{22}$ and in two with premenstrual exacerbations in another study. ${ }^{23}$

Danazol has been shown to be effective in patients with hereditary angioedema resulting in increased levels of $\mathrm{Cl}$ esterase inhibitor and fewer clinical episodes. ${ }^{24} 25$ It has also been found to be effective in the clinical control of facial rash of systemic lupus erythematosus in a patient with hereditary angioedema. ${ }^{26}$ Donaldson and Hess reported the use of danazol $200 \mathrm{mg}$ daily in a similar patient with marked sun sensitivity and 'butterfly' lesions on the face, which resulted in disappearance of the rash and resistance to the normally harmful effects of solar exposure. ${ }^{27}$

In a male patient, however, use of this compound was associated with a 'flare' of his disease, ${ }^{28}$ accompanied by dramatic reductions in his testosterone concentrations. The 
authors concluded that danazol treatment is analogous to castration. It suppressed endogenous androgen production but failed to provide sufficient exogenous androgen. In women, however, danazol suppresses endogenous oestrogen activity and would therefore be expected to produce improvement for this reason.

Thrombocytopenia associated with systemic lupus erythematosus seems to be particularly responsive to this compound and several studies have demonstrated improvement, with remissions lasting from two to 13 months. ${ }^{29} 30$

\section{SYNTHETIC HYDROXYPROGESTERONE DERIVATIVES:}

\section{CYPROTERONE}

Cyproterone, also possessing antigonadotrophic properties by suppressing ovulation, depresses ovarian oestrogen secretion, thus acting as an oral contraceptive. ${ }^{31-33}$ It has antiandrogenic effects, on the skin mainly, and synandrogenic effects on liver and kidney. ${ }^{34}$ It has been widely used to treat acne and hirsutism. It was given to seven female patients with moderately active systemic lupus erythematosus, ${ }^{35}$ and no significant side effects were noted by any patients. The number of clinical exacerbations of systemic lupus erythematosus was lower during cyproterone treatment (27 lupus 'flares' before treatment over 156 patientmonths compared with 15 'flares' during 170 patientmonths with cyproterone treatment), only one patient experiencing a severe 'flare' with glomerulonephritis and nephrotic syndrome after 21 months of cyproterone treatment. The effect on mouth ulceration, particularly, was dramatic-steroid dose and maintenance dosage of hydroxychloroquine were both reduced. The plasma follicle stimulating hormone and luteinising hormone were significantly decreased, with marked decreases in oestradiol concentrations, whereas no effect on male hormone concentrations was seen. Anti-dsDNA levels and C3 and C4 complement concentrations were not altered.

It is always interesting to discuss the possible therapeutic use of new agents in the treatment of disease, and hormones are the most readily available and best studied of all the immunoactive substances known to man. The major problem is simply that the basic immunological effects of these agents in the diseased host are not known and still require extensive investigation. The effects of such agents in the postmenopausal patient with immune disease and the judicious use of birth control agents are beyond the scope of this editorial, but clearly these are important questions which beg answers.

It is likely that appropriate sex steroid therapy with newer compounds presently under development may become useful, adjunctive treatment for lupus patients in the future.

Gender is important, in both the presentation and modulation of autoimmune disease, especially the disease lupus.

Division of Rheumatology and Connective

Tissue Diseases,

RONALD A ASHERSON

St Lukes/Roosevelt Hospital Center,

Columbia University,

New York, NY10019, USA

1 Lahita R G. Sex steroids and the rheumatic diseases. Arthritis Rheum 1985; 28: 121-6.

2 Inman $R$ D. Immunologic sex differences and the female preponderance in systemic lupus erythematosus. Arthritis Rheum 1978; 21: 849-52.
3 Lahita R G. Sex and age in systemic lupus erythematosus. In: Lahita R G, ed. Systemic lupus erythematosus. New York: Wiley, 1986: 523-9.

4 Rose E, Pillsbury D M. Lupus erythematosus (erythematoides) and ovarian function: observations in a possible relationship with a report of 6 cases. Ann Intern Med 1944; 21: 1022-34.

5 Mund A, Swison J, Rothfield N. Effect of pregnancy on the course of SLE. JAMA 1963; 183: 917-20.

6 Jungers P, Dougados M, Pelissier C, et al. Influence of oral contraceptive therapy on the activity of systemic lupus erythematosus. Arthritis Rheum 1982; 25: 618-23.

7 Asherson R A, Derksen R M W M, Bouma B N, et al. Chorea in systemic lupus erythematosus and "lupus-like" disease: association with antiphospholipid antibodies. Semin Arthritis Rheum 1987; 16: 253-9.

8 Asherson R A, Harris E N, Hughes G R V, Farquharson R G. Complications of oral contraceptives and antiphospholipid antibodies. Arthritis Rheum 1988; 31: 373-6.

9 Asherson R A, Harris E N, Gharavi A E, Hughes G R V. Systemic lupus erythematosus, antiphospholipid antibodies, chorea and oral contraceptives. Arthritis Rheum 1986; 29: 1535-6.

10 Lahita R G, Bradlow L, Fishman J, Kunkel H G. Estrogen metabolism in systemic lupus erythematosus patients and family members. Arthritis Rheum 1982; 25: 843-6.

11 Lahita R G, Bradlow H L, Fishman J. Increased 16 alpha hydroxylation of estradiol in systemic lupus erythematosus. 7 Clin Endocrinol Metab 1981; 53: $174-8$.

12 Stimson $\mathrm{W} H$, Hunter I C. Estrogen-induced immunoregulation mediated through the thymus. 7 Clin Lab Immunol 1980; 4: 27-33.

13 Cohen J H M, Danel L, Cordier G, Saez S, Revillard J P. Sex steroid receptors in peripheral $T$ cells: absence of androgen receptors and restriction of estrogen receptors to OKT8 positive cells. $f$ Immunol 1983; 131: tion of estro $2767-71$.

14 Stern R, Fishman J, Brusman H, Kunkel H G. Systemic lupus erythematosus associated with Klinefelter's syndrome. Arthritis Rheum 1977; 20: 18-22.

15 French M A H, Hughes P. Systemic lupus erythematosus and Klinefelter's syndrome. Ann Rheum Dis 1983; 42: 471-3.

16 MacSween R N M. Reticulum cell sarcoma and rheumatoid arthritis in a patient with XY/XXY/XXXY Klinefelter's syndrome and normal intelligence. Lancet 1965; i: 460-1.

17 Lamotte M, Labrousse C, Perrault M A, et al. Polyarthrite rheumatoide severe diabete insulin-resistant syndrome de Klinefelter. Sem Hop Paris 1965; 41: 525-8.

18 Lahita R G, Kunkel H G, Bradlow H L. Increased oxidation of testosterone in systemic lupus erythematosus. Arthritis Rheum 1983; 26: 1517-21.

19 Verheul H A M, Stimson W H, Den Hollander F C, Schuurs A H W M. The effects of nandrolone, testosterone and their decanoate esters on murine lupus. Clin Exp Immunol 1981; 44: 11-17.

20 Hazelton R A, McCruden A B, Sturrock R D, Stimson W H. Hormone manipulation of the immune response in systemic lupus erythematosus: a drug trial of an anabolic steroid, 10-nortestosterone. Ann Rheum Dis 1983; 42: 155-7.

21 Roubinian J R, Talal N, Greenspan J S, Goodman J R, Nussenzweig V. Danazol's failure to suppress autoimmunity in NZB/NSW F1 mice. Arthritis Rheum 1979; 22: $1399-402$.

22 Agnello V, Pariser K, Gell J, Gelfand J, Turksoy R N. Prelminary observation on danazol therapy of systemic lupus: effects on DNA antibodies, thrombocytopenia and complement. $\mathcal{J}$ Rheumatol 1983; 10: antibodie

23 Morley K D, Parke A, Hughes G R V. Systemic lupus erythematosus: two patients treated with danazol. BMF 1982; 284: $1431-4$

24 Gelfand J A, Sherins R J, Alling D W, Frank M M. Treatment of hereditary angioedema with danazol. $N$ Engl f Med 1976; 295: 1444-8.

25 Hauptmann G, Mayer S, Lang J M, Oberling F, Mayer G. Treatment of acquired $\mathrm{Cl}$-inhibitor deficiency with danazol. Ann Intern Med 1977; 85: 577-8.

26 Masse R, Youinou P, Dorval J C, Cledes J. Reversal of lupus erythematosuslike disease with danazol. Lancet 1980 ; ii: 651 .

27 Donaldson V H, Hess E V. Effect of danazol on lupus erythematosus-like disease in hereditary angioneurotic oedema. Lancet 1980; ii: 43.

28 Fretwall M D, Altman L C. Exacerbation of a lupus-erythematosus-like syndrome during treatment of non-Cl-esterase inhibitor-dependent angioedema with danazol. F Allergy Clin Immunol 1982; 69: 306-16.

29 Parisier K, Gell J, Galfand J, et al. Pilot studies in the use of danazol in treatment of patients with systemic lupus erythematosus. [abstract]. Proceedings of the 15th International Congress of Rheumatology, Paris. 1981: 483.

30 Ahn Y S, Harrington W J, Simon S R, Mylvaganam R, Pall L M, So A G. Danazol for the treatment of idiopathic thrombocytopenia purpura. $N E n g l$ f Med 1983; 308: 1396-9.

31 Newmann F. Pharmacology and potential use of cyproterone acetate. Horm Metab Res 1977; 9: 13.

32 Kuttenn F, Rigand C, Wright F, Mauvain-Jarvis P. Treatment of hirsutism by oral cyproterone acetate and percutaneous estradiol. 7 Clin Endocrinol Metab 1980; 51: 1107-11.

33 Lunell N O, Zador G, Carlstrom K, Eneroth P, Patek E, Wager J. The effect of cyproterone acetate on pituitary-ovarian function and clinical symptoms in hirsute women. Acta Endocrinol (Copenh) 1982; 100: 91-7

34 Mowszowicz I, Bieber D E, Chung K W, et al. Synandrogenic and antiandrogenic effect of progestins: comparison with non-progestational antiandrogenic effect of progestins: compariso

35 Jungers $P$, Kuttenn $F$, Liote $F$, et al. Hormonal modulation in systemic lupus erythematosus: preliminary clinical and hormonal results with cyproterone acetate. Arthritis Rheum 1985; 28: 1243-9. 